Assiut University web-site: www.aun.edu.eg

\title{
ROLE OF ESSENTIAL OIL FOR CONTROL OF AVIAN ASPERGILLOSIS IN EXPERIMENTALLY INFECTED CHICKENS
}

\author{
YASMIN SADIEK; T.Y. ABD EL MOTELIB and OMAR AMEN \\ Department of Avian and Rabbit Diseases, Faculty of Veterinary Medicine, Assiut University, Egypt
}

Received: 4 August 2019; Accepted: 10 September 2019

\begin{abstract}
This study was designed to investigate the efficacy of essential oils as an alternative prophylaxis and treatment for avian aspergillosis. The in vitro susceptibility of Aspergillus fumigatus, A.flavus, and A.niger strains to antifungal drugs ( Nystatin, Amphotericin B (AMP ), Ketoconazole (KTC ), Itraconazole (ITR) and Fluconazole (FLU), and to essential oils (Garlic, thyme, cinnamon, tea tree, clove and chamomile oils) was determined using the macro diffusion methods. All fungal isolates demonstrated variable degrees of drugs resistances. All fungi showed $100 \%$ resistance to fluconazole, while ketoconazole is highly effective than itraconazol, amphotericin B and nystatin in all isolated fungi. Essential oils showed antifungal effect especially cinnamon oil followed by clove and garlic among tested EOs in vitro. Cinnamon oil showed the highest inhibition zone diameter to all fungi, so it was chosen for experimental trial based on the obtained antifungal activity results, Cinnamon oil was highly effective against A.fumigatus infection with a dose of $1 \mathrm{ml} \backslash \mathrm{kg}$ ration and could be used in the field of poultry instead of other antifungal drugs.
\end{abstract}

Key word: Essential oils, Cinnamon oil, Aspergillosis

\section{INTRODUCTION}

Aspergillosis is the most common opportunistic mycotic infection of respiratory tract in birds causing high morbidity and mortality thus inducing significant economic losses especially in poultry (Tell, 2005).

Aspergillosis can be acute or chronic form. Acute aspergillosis generally occurs in young birds and resulting in high morbidity and mortality. The chronic form is sporadic and it causes lesser mortality and generally affects older birds, especially a compromised immune system due to poor husbandry condition. Inhalation of A. fumigatus asexual spores (conidia) can cause a spectrum of clinical manifestations depending on the immunological status of the host (Ben-Ami et al., 2010; McCormick et al., 2010).

Although aspergillosis is predominantly a disease of the respiratory tract, all organs can be infected, leading to a variety of manifestations ranging from acute to chronic infections. It is trusted that impaired immunity and the inhalation of a considerable amount of spores are important causative factors (Beernaert et al., 2010).

Corresponding author: Dr. Yasmin Sadiek

E-mail address: yasminali24@yahoo.com

Present address: Department of Avian and Rabbit Diseases,

Faculty of Veterinary Medicine, Assiut University, Egypt
Aspergillosis in poultry is caused by a fungal species under the genus Aspergillus. Organisms cultured from affected organ in decreasing frequency are: Aspergillus fumigates, A. flavus, A. niger, A. glaucus and A. terreus. From these spp, A. fumigatus is a common cause of the disease (salem and ali, 2014).

Treating fungal infections is a challenging task due to the limited number of effective antifungal drugs, the emergence of drug resistance and elevated renal and liver toxicities. Current treatments include the synthetic azoles (e.g. fluconazole and flucytosine) or the natural polyene amphotericin $\mathrm{B}(\mathrm{AmB})$. However usage is becoming limited by resistance development to the azoles, and acute toxicity of AmB. Also, the burden of antifungal resistance is becoming a major concern, and has thus intensified the search for new, safer, and more efficacious agents to combat serious fungal infections (Shreaz et al., 2016).

Essential oils can represent one of the most promising natural products for fungal inhibition, many kinds of EOs obtained from different plants or herbs exhibited intense antifungal properties (Nazzaro et al., 2017).

EOs' antifungal activity may be due to the inhibition of ergosterol biosynthesis and the disruption of membrane integrity and cell wall, which prompted the morphological deformations, collapse and 
deterioration of the conidia and/or hyphae (Pianalto and Alspaugh, 2016).

The fungitoxic properties of essential oil extracted from Cinnamon (Cinnamomum zeylanicum Breyn) bark have been investigated against five species of Aspergillus spp A. flavus, A. fumigatus Fresenius, A. nidulans, A. niger and A. terreus (Srivastava, 2015).

Cinnamon oil strongly inhibited the radial mycelial growth of Aspergillus species and associated with morphological changes as decreased condition, leakage of cytoplasm, loss of pigmentation and disrupted cell structure indicating fungal wall degeneration (Carmo et al., 2008).

To our knowledge, no published data exist for examining Cinnamon oil treatment efficacy for avian aspergillosis in experimentally infected chickens. Therefore, the objectives of this study were (i) evaluation of the in vitro antifungal activity of EOs and antifungal drugs against A. fumigatus, flavus, niger (ii) assessment of cinnamon prophylaxis and treatment efficacy in an experimental avian aspergillosis model.

\section{MATERIALS AND METHODS}

\section{Experimental inoculum}

18 isolated strains (6 A.fumigatus, 6 A.niger, 6 A.flavus) were used for antifungal assay, all 18 strains of avian species with clinical aspergillosis (lungs and air sacs).

Spore suspensions of A. fumigatus, A.flavus, A.niger were prepared in sterile $0.85 \% \mathrm{NaCl}$ with Tween 20 from fresh colonies grown on Sabouraud dextrose agar at $35{ }^{\circ} \mathrm{C}$ for 5 days, Cell concentration was adjusted to final concentrations of $0.4 \times 10^{4}$ to $5 \mathrm{x}$ $10^{4}$. These suspensions were used directly for the inoculation (Espinel-Ingroff et al., 2007).

\section{Screening for antifungal activity of antifungal drugs and EOs in vitro}

\section{Disc diffusion test}

M 44-A (CLSI/NCCLS 2004); (Espinel-Ingroff et al., 2007)

A sterile swab was dipped in the suspension and the excess fluid drained by rotating the swab against the inside of the container, Potato dextrose plates was inoculated from the same suspension, with a fresh swab with a rotary movement. The plates were incubated at $35^{\circ} \mathrm{C}$ for $18-24 \mathrm{~h}$, read, and then incubated for a further $18-24 \mathrm{~h}$ to determine the optimal incubation time. Zone sizes were measured in millimeters with calibers.

The 18 isolated strains (6 A.fumigatus, 6 A.niger, 6 A.flavus) were tested against 5 anti-fungal discs of commonly used chemotherapeutic agents from Oxoid ${ }^{\circledR}$ Hampshire, UK: Nystatin (NY) 100 I.U, Amphotericin B (AMP) $20 \mu \mathrm{g}$, Ketoconazole (KTC) $10 \mu \mathrm{g}$, Itraconazole (ITR) $10 \mu \mathrm{g}$ and Fluconazole (FLU) $25 \mu \mathrm{g}$. The following tentative zone diameter categories were assigned: susceptible, $\geq 17 \mathrm{~mm}$ (azoles and nystatin) and $\geq 15 \mathrm{~mm}$ (amphotericin B (AP)); intermediate, $14-16 \mathrm{~mm}$ (azoles and nystatin) and 13-14 mm (AP); resistant, $\leq 13 \mathrm{~mm}$ (azoles and nystatin) and $\leq 12 \mathrm{~mm}(\mathrm{AP})$.

Agar well diffusion test Balouiri et al. (2016) and Tartor and Hassan (2017)

Garlic, thyme, cinnamon, tea tree, clove and chamomile oils (ELCaptain Company and rose monde company) were screened for antifungal activity using agar well diffusion method.

The agar plate surface is inoculated by spreading $1 \mathrm{ml}$ of the microbial inoculum $\left(5 \times 10^{4}\right)$ over the entire agar surface, then, a hole with a diameter of 6 to $8 \mathrm{~mm}$ is punched aseptically with a sterile cork borer or a tip, and a volume of $50 \mu$ of each essential oils dissolved in DMSO is introduced into the well, then the agar plates are incubated for 48 hour at $37{ }^{\circ} \mathrm{C}$. Zone sizes were measured in millimeters with calibers. Its considered positive when $\geq 10 \mathrm{~mm}$.

Evaluation of cinnamon oil efficacy against A.fumigatus experimentally

A total of 65-0ne day old chicks were used, 5 killed at the beginning of the experiment (pre-inoculation control) lung sections were cultured on SDA plates incubated at $37{ }^{\circ} \mathrm{C}$ and checked for A.fumigatus, the remaining chicks were randomly assigned into 4 equal separated groups.

Chicks in groups 1, 2 (at 3-day-old) were inoculated intratracheally with $1 \mathrm{ml}$ A.fumigatus spore $\left(2,7 \times 10^{6}\right)$ detected by spectrophotometer (Hereba et al., 2016), chickens in group 2 were treated with $(1 \mathrm{ml} / \mathrm{kg}$ diet)cinnamon oil (the most effective in vitro sensitivity) and treatment started at the day of infection and continued for 15 days. Group 3, chicks were taken cinnamon oil $(1 \mathrm{ml} / \mathrm{kg}$ diet $)$ for 15 day. Group 4, served as uninfected untreated control (negative control). All clinical signs, postmortem lesions and mortalities were recorded. At the end of the experiment, the remaining chicks were sacrificed and subjected to post mortem and mycological examination. 


\section{RESULTS}

Table 1: Sensitivity of A. fumigatus strains to antifungal drugs.

\begin{tabular}{ccccccc}
\hline \multirow{2}{*}{ Antifungal drugs } & \multicolumn{2}{c}{ Interpretation of zone diameter $(\mathrm{mm})$} & & \multicolumn{2}{c}{ Result (n=6) } \\
& \multicolumn{2}{c}{ (Espinel-Ingroff et al., 2009) } & & & \\
& Resistant & Intermediate & Sensitive & Resistant\% & Intermediate\% & Sensitive\% \\
\hline Nystatin & $\leq 13$ & $14-16$ & $\geq \mathbf{1 7}$ & $\mathbf{6 7}$ & $\mathbf{3 3}$ & $\mathbf{0}$ \\
\hline Itraconazole & $\leq 13$ & $14-16$ & $\geq \mathbf{1 7}$ & $\mathbf{5 0}$ & $\mathbf{5 0}$ & $\mathbf{0}$ \\
\hline Ketoconazole & $\leq 13$ & $14-16$ & $\geq \mathbf{1 7}$ & $\mathbf{0}$ & $\mathbf{3 3}$ & $\mathbf{6 7}$ \\
\hline Fluconazole & $\leq 13$ & $14-16$ & $\geq \mathbf{1 7}$ & $\mathbf{1 0 0}$ & $\mathbf{0}$ & $\mathbf{0}$ \\
\hline Amphotericin B & $\leq 12$ & $13-14$ & $\geq \mathbf{1 5}$ & $\mathbf{6 7}$ & $\mathbf{3 3}$ & $\mathbf{0}$ \\
\hline
\end{tabular}

A.Fumigatus isolates showed $100 \%$ resistant to Fluconazole, $67 \%$ resistant to both Nystatin and Amphotericin B while $50 \%$ resistant to Itraconazole and only sensitive to Ketoconazole with $67 \%$

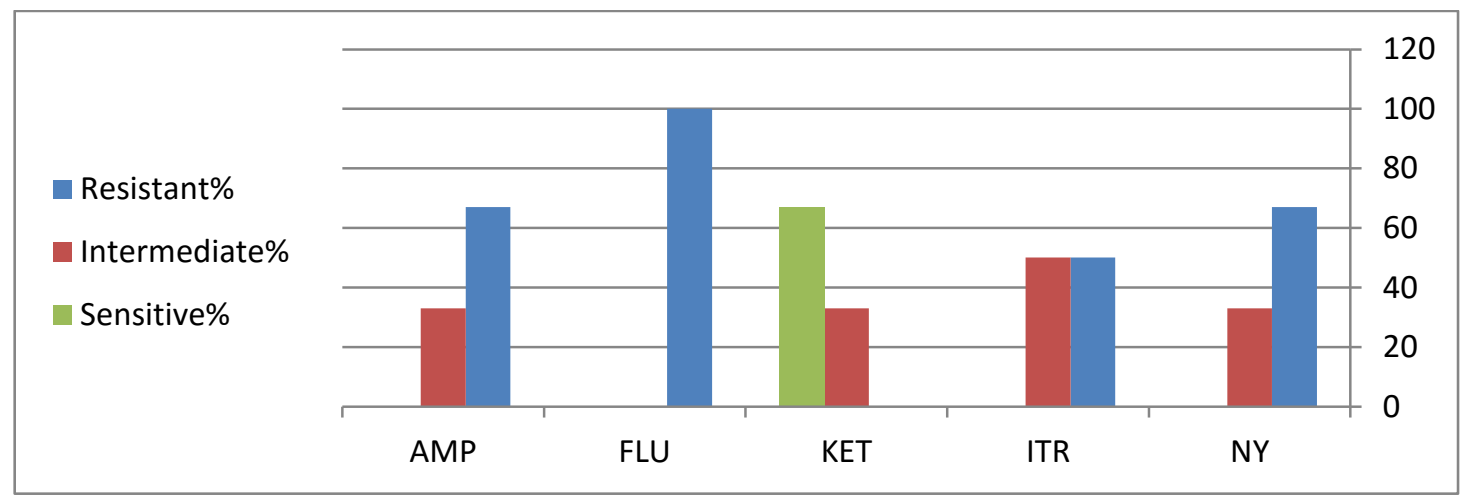

Figure (1): Degree of sensitivity of Aspergillus fumigatus to antifungal drugs - disk diffusion method

Table 2: Sensitivity of $A$. flavus strains to antifungal drugs.

\begin{tabular}{ccccccc}
\hline \multirow{2}{*}{ Antifungal drugs } & \multicolumn{2}{c}{$\begin{array}{l}\text { Interpretation of zone diameter }(\mathrm{mm}) \\
\text { (Espinel-Ingroff } \text { et al., 2009) }\end{array}$} & \multicolumn{2}{c}{ Result } \\
\cline { 2 - 7 } & Resistant & Intermediate & Sensitive & Resistant\% & Intermediate\% & Sensitive\% \\
\hline Nystatin & $\leq 13$ & $14-16$ & $\geq \mathbf{1 7}$ & $\mathbf{1 0 0}$ & $\mathbf{0}$ & $\mathbf{0}$ \\
\hline Itraconazole & $\leq 13$ & $14-16$ & $\geq \mathbf{1 7}$ & $\mathbf{1 0 0}$ & $\mathbf{0}$ & $\mathbf{0}$ \\
\hline Ketoconazole & $\leq 13$ & $14-16$ & $\geq \mathbf{1 7}$ & $\mathbf{0}$ & $\mathbf{0}$ & $\mathbf{1 0 0}$ \\
\hline Fluconazole & $\leq 13$ & $14-16$ & $\geq \mathbf{1 7}$ & $\mathbf{1 0 0}$ & $\mathbf{0}$ & $\mathbf{0}$ \\
\hline Amphotericin B & $\leq 12$ & $13-14$ & $\geq \mathbf{1 5}$ & $\mathbf{1 0 0}$ & $\mathbf{0}$ & $\mathbf{0}$ \\
\hline
\end{tabular}

A.flavus isolates showed $100 \%$ resistant to Fluconazole, Itraconazole, Nystatin and Amphotericin B while $100 \%$ susceptible to Ketoconazole.

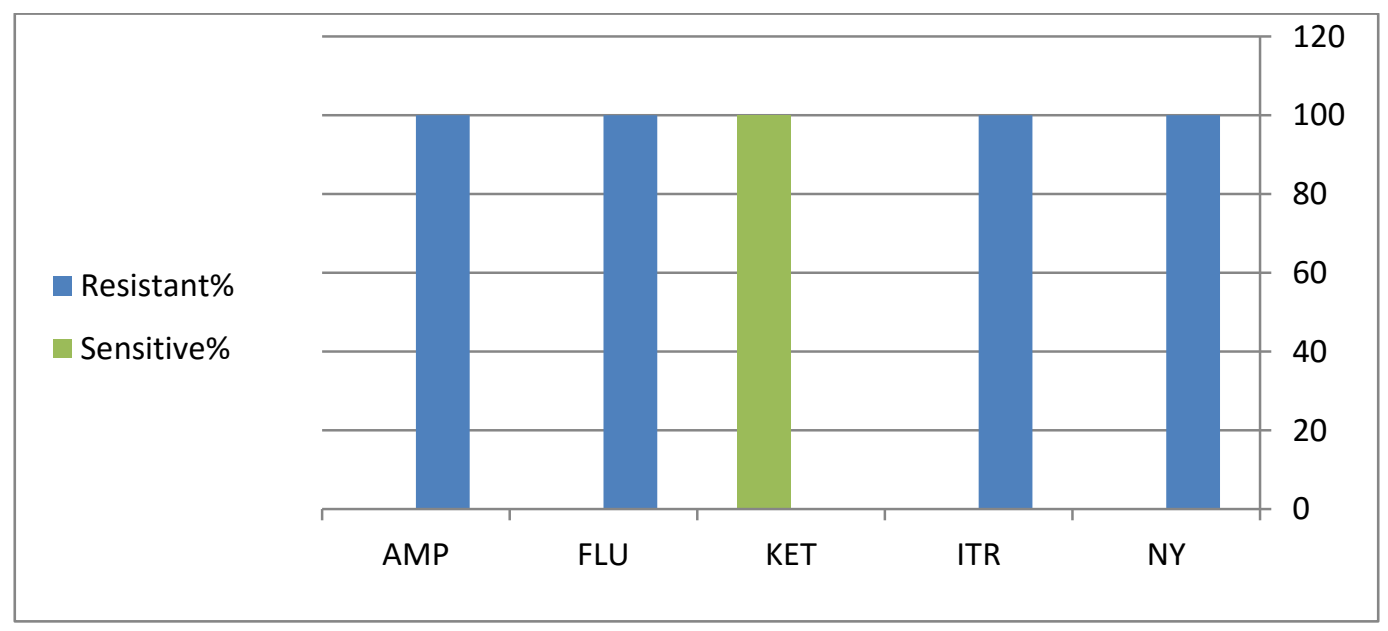

Figure (2): Degree of sensitivity of Aspergillus flavus to antifungal drugs - disk diffusion method. 
Table 3: Sensitivity Susceptibilities of A. niger strains to antifungal drugs.

\begin{tabular}{ccccccc}
\hline & \multicolumn{3}{c}{$\begin{array}{c}\text { Interpretation of zone diameter (mm) } \\
\text { (Espinel-Ingroff et al.,2009) }\end{array}$} & \multicolumn{2}{c}{ Result } \\
\cline { 2 - 7 } Antifungal drugs & Resistant & Intermediate & Sensitive & Resistant\% & Intermediate\% & Sensitive\% \\
\hline Nystatin & $\leq 13$ & $14-16$ & $\geq \mathbf{1 7}$ & $\mathbf{5 0}$ & $\mathbf{5 0}$ & $\mathbf{0}$ \\
\hline Itraconazole & $\leq 13$ & $14-16$ & $\geq \mathbf{1 7}$ & $\mathbf{1 0 0}$ & $\mathbf{0}$ & $\mathbf{0}$ \\
\hline Ketoconazole & $\leq 13$ & $14-16$ & $\geq \mathbf{1 7}$ & $\mathbf{0}$ & $\mathbf{1 7}$ & $\mathbf{8 3}$ \\
\hline Fluconazole & $\leq 13$ & $14-16$ & $\geq \mathbf{1 7}$ & $\mathbf{1 0 0}$ & $\mathbf{0}$ & $\mathbf{0}$ \\
\hline Amphotericin B & $\leq 12$ & $13-14$ & $\geq \mathbf{1 5}$ & $\mathbf{5 0}$ & $\mathbf{5 0}$ & $\mathbf{0}$ \\
\hline
\end{tabular}

A.niger strains isolates showed $100 \%$ resistant to Fluconazole and Itraconazole while $50 \%$ resistance to Nystatin and Amphotericin B while only susceptible to ketoconazole with $83 \%$.

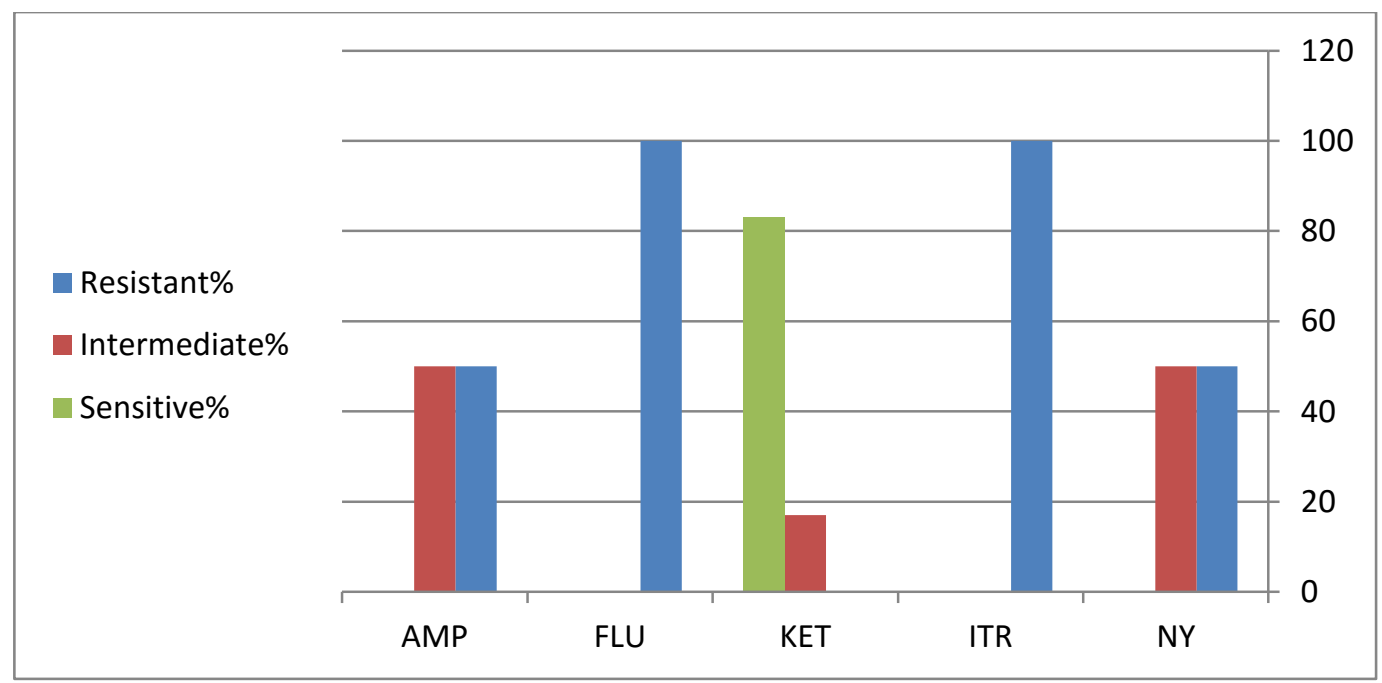

Figure (3): Degree of sensitivity of Aspergillus niger to antifungal drugs - disk diffusion method.

\begin{abstract}
Results of sensitivity of fungi isolates to different essential oils $(n=6)$ :

Sensitivity of $\boldsymbol{A}$. fumigatus strains to essential oils

Cinnamon oil, tea tree oil and clove oil displayed antifungal activity for A.fumigatus isolates, with the highest efficacy by Cinnamon oil. Cinnamon oil showed the highest inhibition zone diameter $(27 \pm 2$ $\mathrm{mm})$ followed by tea tree oil $(13 \pm 2 \mathrm{~mm})$, and clove $(12.5 \pm 1 \mathrm{~mm})$. Garlic oil has moderate activity (10 $\pm 1 \mathrm{~mm}$ ), thyme oil and chamomile oil did not exhibit any antifungal sensitivity for A.fumigatus isolates. Cinnamon oil was chosen for experimental trial in vivo based on the obtained antifungal activity results.
\end{abstract}

\section{Sensitivity of $\boldsymbol{A}$. flavus strains to essential oils}

Cinnamon oil, garlic oil and clove oil displayed antifungal activity for A.flavus isolates, with the highest efficacy by Cinnamon oil, which showed the highest inhibition zone diameter $(27.8 \pm 3 \mathrm{~mm})$ followed by garlic oil $(12.3 \pm 2 \mathrm{~mm})$, and clove oil (10 $\pm 2 \mathrm{~mm}$ ), chamomile oil, thyme oil and tea tree oil did not exhibit any antifungal sensitivity for A.flavus isolates.

Sensitivity of $\boldsymbol{A}$. niger strains to essential oils Cinnamon oil, clove oil and garlic oil displayed antifungal activity for A.niger isolates, with the highest efficacy by Cinnamon oil, which showed the highest inhibition zone diameter $(26.8 \pm 1 \mathrm{~mm})$ followed by clove oil $(14.5 \pm 1.5 \mathrm{~mm})$, and garlic oil $(11.8 \pm 2 \mathrm{~mm})$, chamomile oil has weak activity $(9.7 \pm 2 \mathrm{~mm})$, thyme oil and tea tree oil did not exhibit any antifungal sensitivity. 


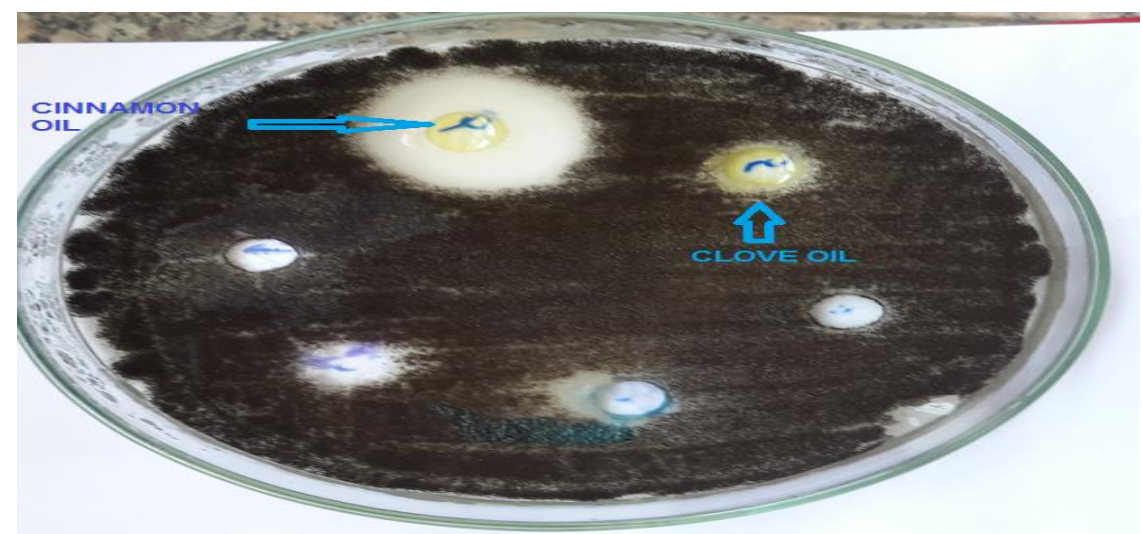

Figure(4): Agar well diffusion test showing susceptability of A.niger to cinnamon oil and clove oil.

\section{Results of Experimental design:}

Clinical signs: (Group 1): Two days after the inoculation, general and respiratory signs of aspergillosis were observed. Clinical signs included ruffled feathers, gasping, dyspnea, dullness, greenish watery diarrhea, loss of weight, cloudy eye and anorexia. Deaths were recorded starting from the third day of the inoculation. All chicks in infected untreated group (group 1) died within 15 days post the inoculation. While in infected and treated group (group 2), 10 chicks (66.7\%) survived and no deaths or clinical signs were occurred after day 8 post inoculation.

(Groups 3, 4): Neither death nor clinical signs of aspergillosis were observed in both treated and control groups.

Post mortem: The birds in all groups were necropsied and the most common gross findings were noticed in Group (1). There were whitish cheesy materials of fungal growth appeared dispersed in the air sacs and lung tissue. Marked congestion of the lungs and thickening of the air sac membranes occur were observed. Miliary necrotic foci develop in lungs around the sites of fungal growth and result in the formation of nodules. These nodules were discrete, circumscribed, and white in color and randomly distributed throughout the lung tissue and air sac, myocardium, thoracic wall and abdominal serosa, some cases showed congested kidney. (Group 2): This lesion observed in only 5 dead birds from treated group and disappeared after 8 day post infection (day 10). (Group 3, 4): no post mortem lesions were observed.

In (Group 1): the inoculated A.fumigatus was reisolated from the lungs, air sacs from all infected chicks, while in (Group 2): the inoculated A.fumigatus was re-isolated from the lungs, air sacs from the only five dead birds and re-isolation was unsuccessful in the survivor chicks.

Table 4: Mortality percent in the four groups.

\begin{tabular}{|c|c|c|c|c|c|c|c|c|c|c|c|c|c|c|c|c|c|c|c|c|c|}
\hline $\begin{array}{c}\text { Days } \\
\text { (PI) }\end{array}$ & 1 & 2 & 3 & 4 & 5 & 6 & 7 & 8 & 9 & 10 & 11 & 12 & 13 & 14 & 15 & $\begin{array}{l}16- \\
30\end{array}$ & 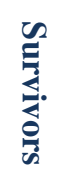 & 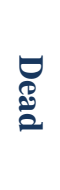 & $\stackrel{\overrightarrow{0}}{\stackrel{0}{0}}$ & 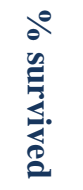 & $\frac{\partial^{9}}{\stackrel{0}{ٍ:}}$ \\
\hline $\begin{array}{c}\text { GROUP 1 } \\
\mathbf{N}=15 \\
\text { Infected } \\
\text { untreated }\end{array}$ & - & - & 1 & 1 & 2 & 2 & - & 2 & - & - & 2 & 2 & 1 & 1 & 1 & - & 0 & 15 & 15 & 0 & 100 \\
\hline $\begin{array}{c}\text { GROUP } 2 \\
\mathbf{N}=\mathbf{1 5} \\
\text { Infected treated }\end{array}$ & - & - & 1 & 1 & 2 & - & - & 1 & - & - & - & - & - & - & - & - & 10 & 5 & 15 & 66.7 & 33.3 \\
\hline $\begin{array}{c}\text { GROUP 3 } \\
\mathbf{N = 1 5} \\
\text { Take cinnamon } \\
\text { oil in ration } \\
\end{array}$ & - & - & - & - & - & - & - & - & - & - & - & - & - & - & - & - & 15 & 0 & 15 & 100 & 0 \\
\hline $\begin{array}{c}\text { GROUP 4 } \\
\mathbf{N}=\mathbf{1 5} \\
\text { (negative } \\
\text { control) }\end{array}$ & - & - & - & - & - & - & - & - & - & - & - & - & - & - & - & - & 15 & 0 & 15 & 100 & 0 \\
\hline
\end{tabular}




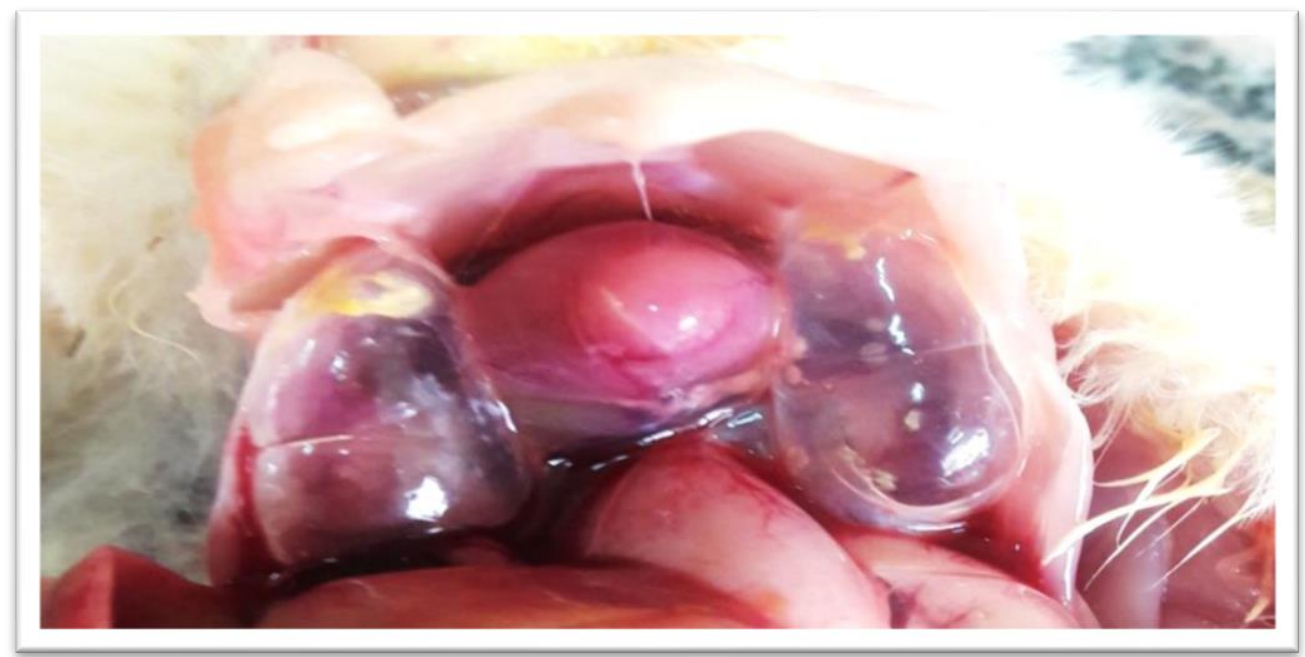

Figure (5): Air sacs are thickened and lung tissues contain a lot of Miliary necrotic foci around the sites of fungal growth.

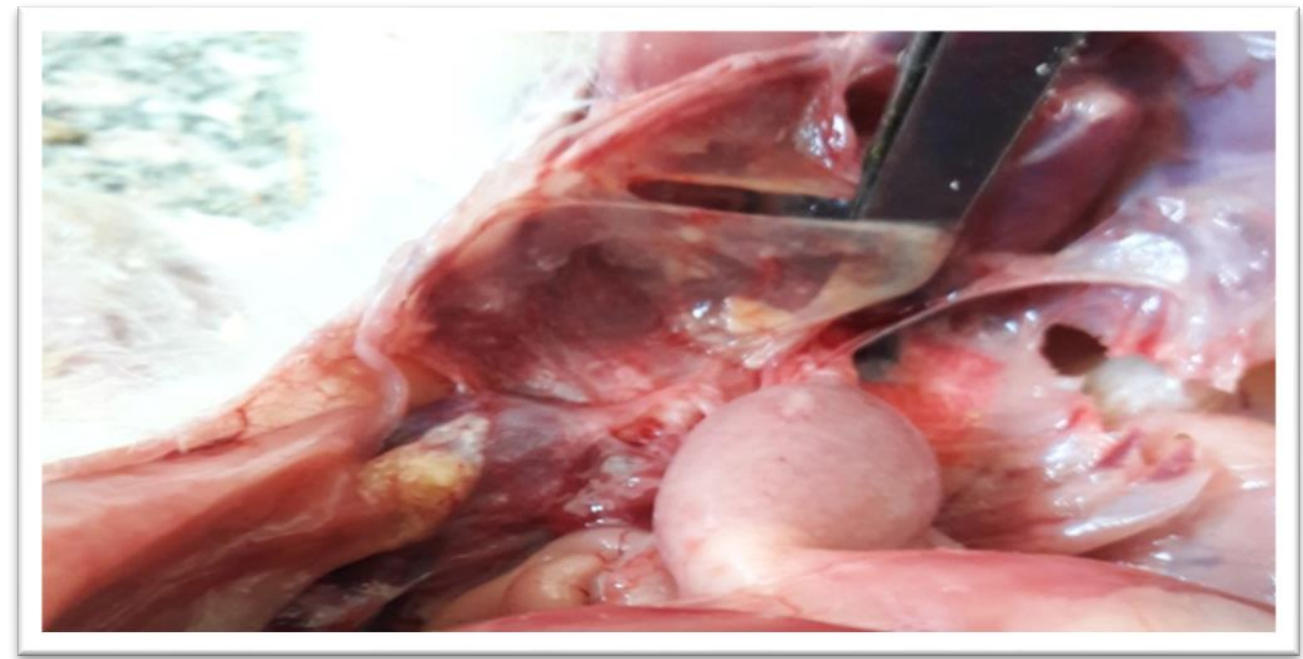

Figure (6): lung showing discrete, circumscribed, white in color and randomly distributed nodules throughout the lung tissues.

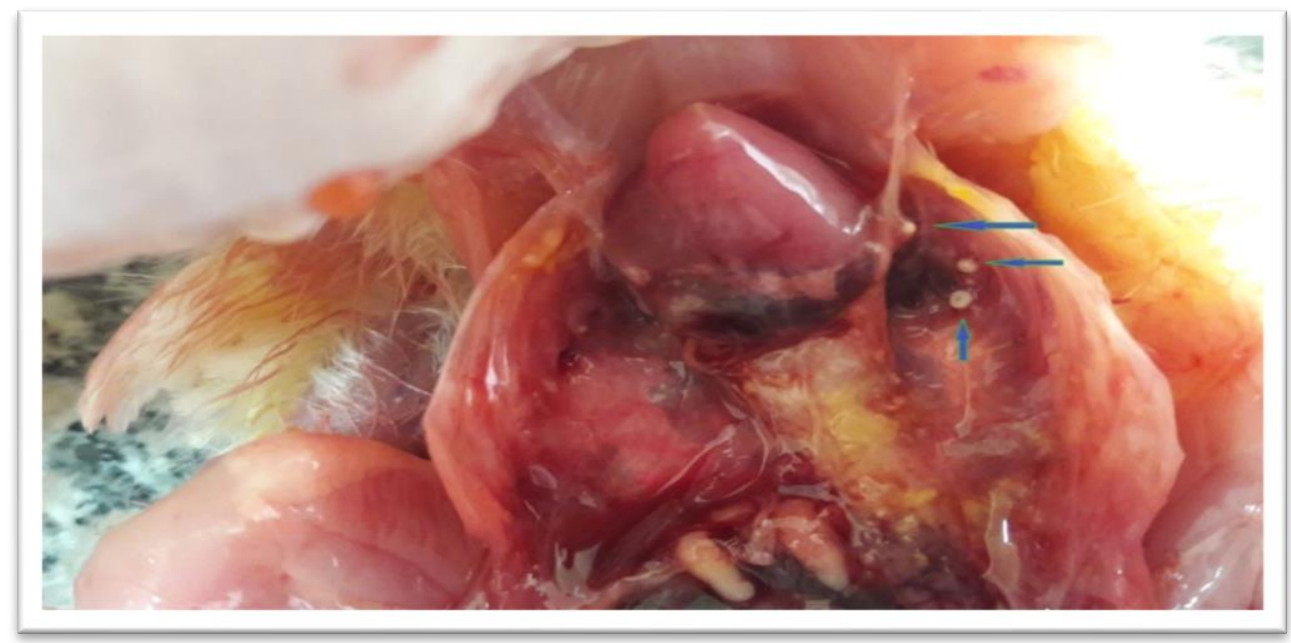

Figure (7): Air sacs are thickened and coverd with small whitish cheesy materials of fungal growth. 


\section{DISCUSSION}

In recent years, a fungal infection have emerged as a world-wide health problem and has become an important cause of respiratory infection in poultry owing to extensive use of broad spectrum antibiotics, corticosteroids and increasing population of terminally ill and debilitated patients which trigger an interest to examine the source and reservoir of such fungi. Among the infectious diseases fungal diseases have their own importance and seem to be one of the great obstacles for the poultry farmers in the form of high morbidity, mortality and production losses Asfaw and Dawit (2017).

In vitro sensitivity of our fungal isolates to 5 antifungal drugs showed that A.Fumigatus isolates showed $100 \%$ resistant to Fluconazole, 67\% resistant to both Nystatin and Amphotericin B while $50 \%$ resistant to Itraconazole and only sensitive to Ketoconazole with $67 \%$. Our results agreed to some extend with those reported by Ziółkowska et al. (2014) and Tartor and Hassan (2017) in case of Fluconazole, Amphotericin B and Itraconazole, except in case of ketoconazole who found that most strain of A.fumigatus was resistant to it.

Our isolates of A.flavus showed $100 \%$ resistant to Fluconazole, Itraconazole, Nystatin and Amphotericin B, while $100 \%$ susceptible to Ketoconazole. These results were totally in agreement with Kumar et al. (2010) in case of Fluconazole and Ketoconazole but totally disagreed in case of Itraconazole and Amphotericin B, this may be due to the difference in countries.

Aspergillus.niger strains isolates showed $100 \%$ resistant to Fluconazole, Itraconazole, $50 \%$ resistance to Nystatin and Amphotericin B while only susceptible to ketoconazole with $83 \%$. These results accepted with those mentioned by Tokarzewski et al. (2012). It can be assumed that as in the case of other Aspergillus species, the effectiveness of antifungal agents may depend not only on the type of fungus, but also on the site of isolation (environment, patient), and even the species of the host (human, animal, bird) (Tokarzewski et al., 2012).

In vitro sensitivity of our fungal isolates to $6 \mathrm{EOs}$ showed that in case of A.fumigatus: cinnamon oil, tea tree oil and clove oil displayed antifungal activity for A.fumigatus isolates, with the highest efficacy by cinnamon oil, which showed the highest inhibition zone diameter $(27 \pm 2 \mathrm{~mm})$ followed by tea tree oil $(13 \pm 2 \mathrm{~mm})$, and clove $(12.5 \pm 1 \mathrm{~mm})$. Garlic oil has moderate activity $(10 \pm 1 \mathrm{~mm})$, thyme oil and chamomile oil did not exhibit any antifungal sensitivity for A.fumigatus isolates. These results were in agreement with that reported by Singh et al. (1995); Inouye et al. (2000); Carmo et al. (2008); Rana et al. (2011); Srivastava (2015) and Tartor and Hassan (2017).

Concerning to in vitro sensitivity of A. Flavus to tested EOs: cinnamon oil, garlic oil and clove oil displayed antifungal activity for A.flavus isolates, with the highest efficacy by cinnamon oil, which showed the highest inhibition zone diameter (27.8 $\pm 3 \mathrm{~mm})$ followed by garlic oil $(12.3 \pm 2 \mathrm{~mm})$, and clove oil $(10 \pm 2 \mathrm{~mm})$, while chamomile oil, thyme oil and tea tree oil did not exhibit any antifungal sensitivity for A.flavus isolates.

These results were similar to that mentioned by Singh et al. (1995); Carmo et al. (2008); Gutiérrez et al. (2010); Rana et al. (2011) and Srivastava (2015).

Our result in vitro sensitivity of $A$. niger to tested EOs: cinnamon oil, clove oil and garlic oil displayed antifungal activity for A.niger isolates with the highest efficacy by cinnamon oil, which showed the highest inhibition zone diameter $(26.8 \pm 1 \mathrm{~mm})$ followed by clove oil $(14.5 \pm 1.5 \mathrm{~mm})$, and garlic oil $(11.8 \pm 2 \mathrm{~mm})$. Chamomile oil has weak activity $(9.7 \pm 2 \mathrm{~mm})$ while thyme oil and tea tree oil did not exhibit any antifungal sensitivity. These result were in agreement with that illustrated by Tansey and Appleton, (1975); Singh et al. (1995); Carmo et al. (2008); Rana et al. (2011) and Srivastava (2015).

General and respiratory signs of aspergillosis in experimentally infected birds were observed two days after the inoculation in group 1 and in some chicks in experimentally infected and treated birds in group 2. Clinical signs included ruffled feathers, gasping, dyspnea, dullness, green watery diarrhea, loss of weight, cloudy eye and anorexia. These signs were similar to those described by Atasever and Gümüssoy, (2004); Gümüssoy et al. (2004). All chicks in infected untreated group (group 1) died within 15 days after the inoculation, this was similar to that found by Fadl Elmula et al. (1984) and agreed to certain degree with Peden and Rhoades, (1992); Le Loc'h et al. (2006). While in infected treated birds (group 2), 10 chicks $(66.7 \%)$ survived and no death or clinical signs occurred after day 8 post inoculation, so the cinnamon oil reduced the mortality rate between the chicks, while in only treated birds (group 3) or control groups (group 4) neither death nor clinical signs of aspergillosis were observed. These was going hand by hand with that mentioned by Symeon et al. (2014) who found that cinnamon oil at the selected concentrations $(0.5$ and $1 \mathrm{ml} / \mathrm{kg}$ feed) may not have the potential to influence mortality rates and Atasever and Gümüssoy (2004) who found that the controled group don't have any clinical sign or mortality. 


\section{REFERENCES}

Asfaw, M. and Dawit, D. (2017): Review on Major Fungal Disease of Poultry. British Journal of Poultry Sciences, 6 (1): 16-25.

Atasever, A. and Gümüssoy, S.K. (2004): Pathological, Clinical and Mycological Findings in Experimental Aspergillosis Infections of Starlings. . Vet. Med. A, 51: 1922.

Balouiri, M.; Sadiki, M. and Ibnsouda, K.S. (2016): Methods for in vitro evaluation antimicrobial activity: A review.Journal of Pharmaceutical Analysis, 6(2): 71-79.

Beernaert, A.L.; Pasmans, F.; Van Waeyenberghe, L.; Haesebrouck, F. and Martel, A. (2010): Aspergillus infections in birds: a review. Avian Pathology, 39(5): 325331.

Ben-Ami, R.; Lewis, R.E. and Kontoyiannis, D.P. (2010): Enemy of the (immunosuppressed) state: an update on the pathogenesis of Aspergillus fumigatus infection. British Journal of Haematology, 150: 406-417.

Carmo, E.S.; Lima, E.O.; De Souza, E.L. and De Sousa, F.B. (2008): Effect of cinnamomum zeylanicum blume essential oil on the growth and morphogenesis of some potentially pathogenic Aspergillus Species. Braz. J. Microbiol., 39: 91-97.

CLSI/NCCLS (2004): National Committee for Clinical Laboratory Standards. (2004) Reference method for antifungal disc diffusion $132 \mathrm{~S}$. Tokarzewski et al. susceptibility testing of yeasts. Approved standard, 2nd ed. NCCLS document M44-A. Clinical Laboratory Standards Institute. Wayne, PA.

Espinel-Ingroff, A.; Arthington-Skaggs, B.; Iqbal, N.; Ellis, D.; Pfaller, M.A.; Messer, S.; Rinaldi, M.; Fothergill, A.; Gibbs, D.L. and Wang, A. (2007): Multicenter evaluation of a new disk agar diffusion method for susceptibility testing of filamentous fungi with voriconazole, posaconazole, itraconazole, amphotericin B, and caspofungin. J Clin Microbiol 45: 1811-1820.

Espinel-Ingroff, A.; Canton, E. and Javier, $P$. (2009): Updates in Antifungal Susceptibility Testing of Filamentous Fungi. Current Fungal Infection Reports, Virginia Commonwealth University Medical Center 3: 133-141.

Fadl-elmula, A.; Abu-elgasim, A. and El-mubarak, A.K. (1984): Experimental aspergillosis in young chicks. Rev. Elev. Méd. vét. Pays trop, 37 (4): 437-441.

Gümüssoy, S.K.; Uyanik, F.; Atasever, A. and Cam, $Y$. (2004): Experimental Aspergillus fumigatus Infection in Quails and Results of Treatment with Itraconazole. J. Vet. Med. B 51: 34-38.
Gutiérrez, L.; Batlle, R.; Sánchez, C. and Nerín, C. (2010): New approach to study the mechanism of antimicrobial protection of an active packaging. Foodborne Pathog. Dis., 7: 1063-1069.

Hereba, M.A.; Shathele, S.M. and Hamouda, A.M. (2016): Studies on experimental infection with Aspergillus fumigatus in ostrich chicks, The Journal of Animal \& Plant Sciences, 26(6): 1609-1613.

Inouya, S.; Tsuruoka, T.; Watanabe, M.; Takeo, K.; Akao, M.; Nishiyama, Y. and Yamaguchi, H. (2000): Inhibitory effect of essential oils on apical growth of Aspergillus fumigatus by vapour contact. Mycoses, 43(1-2): 17-23.

Kumar, R.; Shrivastava, K.S. and Chakraborti, A. (2010): Comparison of Broth Dilution and Disc Diffusion Method for the Antifungal Susceptibility Testing of Aspergillus flavus. Am. J. Biomed. Sci, 2(3), 202-208.

Le loc'h, G.; Arne, P. and Bourgerol, C. (2006): Detection of circulating serum galactomannan for the diagnosis of avian aspergillosis. Proceedings of the 16th Congress of the International. Society for Human and Animal Mycology, Paris, France, June 2006.

McCormick, A.; Loeffler, J. and Ebel, F. (2010): Aspergillus fumigatus: contours of an opportunistic human pathogen. Cellular Microbiology, 12: 1535-1543.

Nazzaro, F.; Fratianni, F.; Coppola, R. and Feo, D.V. (2017): Essential Oils and Antifungal Activity. Pharmaceuticals, 10(4): 1-20.

Peden, W.M. and Rhoades, K.R. (1992): Pathogenicity differences of multiple isolates of Aspergillus fumigatus in turkeys. Avian Diseases, 36 (3): 537-542.

Pianalto, K. and Alspaugh, J. (2016): New horizons in antifungal therapy. J Fungi, 2( 26): 1-24.

Rana, I.S.; Rana, A.S. and Rajak, R.C. (2011): Evaluation of antifungal activity in essential oil of the Syzygium aromaticum (L.) by extraction, purification and analysis of its main component eugenol. Brazilian Journal of Microbiology, 42(4): 1269-1277.

Salem, A.M.L. and Ali, A. (2014): Epidemiological study of Aspergillosis in chickens and human contacts in chicken farms at Kalyoubia Governorate. IOSR Journal of Agriculture and Veterinary Science (IOSR-JAVS). 7 (7): 20-24.

Shreaz, S.; Wani, A.W.; Behbehani, M.J.; Raja, V.; Irshad, M.; Karched, M.; Ali, I.; Siddiqi, A.W. and Hun, T.L. (2016): Cinnamaldehyde and its derivatives, a novel class of antifungal agents. Fitoterapi 112: 116-131.

Singh, H.B.; Srivastava, M.; Singh, A.B. and Srivastava, A.K. (1995): Cinnamon bark oil, a potent fungitoxicant against fungi causing 
respiratory tract mycoses. Allergy, 50: 995999.

Srivastava, N. (2015): In vitro assesment of fungitoxicity of cinnamon bark oil against aspergillus sp International Journal of Pharma and Bio Sciences 6(1): 656-663.

Symeon, K.G.; Athanasiou, A.; Lykos, N.; Charismiadou, A.M.; Goliomytis, M.; Demiris, N., Ayoutanti, A.; Simitzis, E.P. and Deligeorgis, G.S. (2014): The effects of dietary cinnamon (Cinnamomum zeylanicum) oil supplementation on broiler feeding behaviour, growth performance, carcass traits and meat quality characteristics. Ann. Anim, 14(4) 883-895.

Tansey, M.R. and Appleton, J.A. (1975): Inhibition of fungal growth by garlic extract. Mycologia 67: 409-413.

Tartor, H.Y. and Hassan, M.A.F. (2017): Assesment of carvacrol for control of avian aspergillosis in intratracheally challenged chickens in comparison to voriconazole with referenc on economic impact. J of Applied microbiology, 123:1088-1099.

Tell, L.A. (2005): Aspergillosis in mammals and birds: impact on veterinary medicine. Medical Mycology, 43 Suppl 1: 71-73.

Tokarzewski, S.; Ziółkowska, G. and Nowakiewicz, A. (2012): Susceptibility testing of Aspergillus niger strains isolated from poultry to antifungal drugs - a comparative study of the disk diffusion, broth microdilution (M 38-A) and Etest ${ }^{\circledR}$ methods. Polish Journal of Veterinary Sciences 15(1): 125-133.

Ziótkowska, G.; Tokarzewski, S. and Nowakiewicz, A. (2014): Drug resistance of Aspergillus fumigatus strains isolated from flocks of domestic geese in Poland. Poultry Science, 93: 1106-1112.

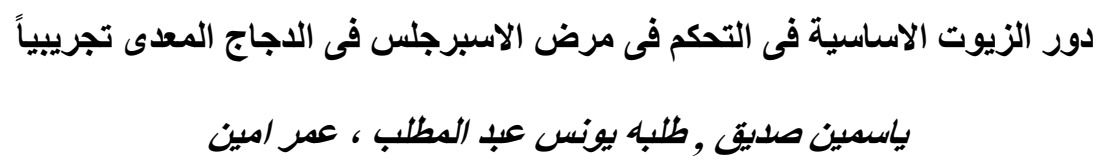

E-mail: yasminali24@yahoo.com_Assiut University web-site: www.aun.edu.eg

تهدف الدر اسه الى تقيم تاثير بعض الزيوت الطبيعيه على بعض انو اعضى الفطريات ومقارنتها ببعض الادويه المضاده للفطريات معمليا

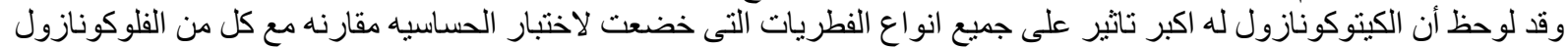

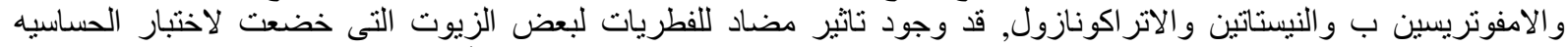

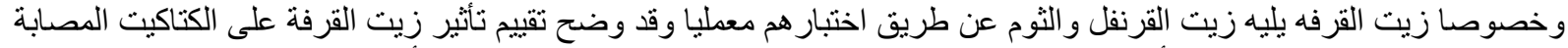

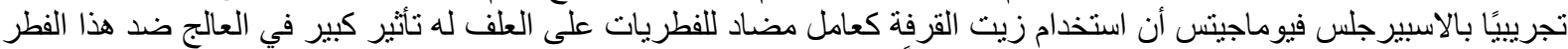

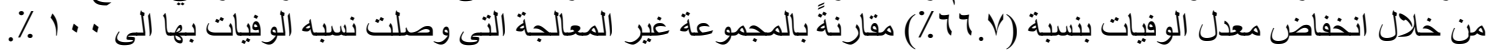

